\title{
O Funil de Inovação como Modelo para Priorizar e Executar Projetos de Tecnologia da Informação
}

\author{
Francisco M. M. da Silva ${ }^{1}$, Violeta Sun ${ }^{1}$, João P. de Albuquerque ${ }^{2}$, Edmir P. V. \\ Prado $^{1}$ \\ ${ }^{1}$ Escola de Artes, Ciências e Humanidades - Universidade de São Paulo (USP) \\ CEP: 03.828-000 - São Paulo - SP - Brasil \\ ${ }^{2}$ Escola de Engenharia de São Carlos - Universidade de São Paulo (USP) \\ CEP: 13.566-590 - São Carlos - SP - Brasil \\ ffrancisco.massaro@gmail.com, violeta@usp.br, jporto@icmc.usp.br, \\ eprado@usp.br\}
}

\begin{abstract}
Organizing properly and formally Information Technology (IT) projects prioritization and implementation activities in search for solutions to bring business value, is a critical task for organizations, from those that use IT as a strategic asset, to those that use its resources as tools to improve operational efficiency. This paper focus on discussing the importance of adopting a formal model for IT Project Management called "Innovation Funnel", presenting related concepts and brings the case study of a multinational Consumer Goods company. The study also presents an analysis of the strengths and improvement opportunities found in the model.
\end{abstract}

Resumo. Organizar devidamente e formalmente as atividades de priorização e execução de projetos de Tecnologia da Informação (TI), em busca de soluções de valor para o negócio, é uma tarefa crítica para as organizações, desde as que utilizam a TI como um ativo estratégico até as que fazem uso de seus recursos como ferramentas de auxílio à eficiência operacional. Este artigo discute a importância da adoção de um modelo formal para o Gerenciamento de Projetos de TI chamado "Funil de Inovação", apresentando conceitos relacionados e por meio da análise de um estudo de caso em uma empresa multinacional de Bens de Consumo. O estudo apresenta também uma análise das potencialidades e oportunidades de melhoria para esse modelo.

\section{Introdução}

Um projeto pode ser compreendido como um empreendimento temporário, ou seja, um esforço que possui início, meio e fim definidos, e que visa o desenvolvimento de um produto ou serviço único (PMI, 2013). Dessa definição é possível extrair duas características interessantes do projeto: a primeira relacionada ao seu ciclo de vida estabelecido e temporal - e que o resultado de um projeto pode ser considerado algo único e exclusivo, nunca antes feito.

O Gerenciamento de Projetos, que desde a década de 60 vem sendo formalmente empregado pelas organizações, favorece essas duas características básicas dos projetos, procurando tornar viável e estruturado todo o seu ciclo de vida, desde sua origem como ideia até a sua entrega. Pelos diversos benefícios obtidos com a utilização do Gerenciamento de Projetos, as empresas que adotam suas práticas se tornam mais 
competitivas diferenciando-se e destacando-se no mercado, pois há um direcionamento básico para que as iniciativas sejam entregues com foco na qualidade do produto ou serviço que está sendo desenvolvido e na entrega dentro do prazo e custo.

Em complemento, a área de Tecnologia da Informação (TI) também oferece suporte para obtenção de vantagem competitiva, uma vez que figura como importante agente no processo de transformação organizacional, provendo o acesso às informações no tempo necessário para a tomada de decisão e também atuando na entrega de inovações tecnológicas de valor para suportar o negócio [Laudon e Laudon 2013; Vanhaverbeke 2013]. Devido a essa última característica, o Gerenciamento de Projetos tem uma importância crucial para a TI.

Em resumo, o presente artigo apresenta um modelo formal para o Gerenciamento de Projetos de TI, o Funil de Inovação [Clark e Wheelwright 1993], como proposta para endereçar um dos desafios que as organizações possuem, conforme Helena e Medeiros (2009) e Laurindo (2008), de priorizar e executar projetos a fim de criar inovações de valor para seus negócios. O Funil de Inovação é, primeiramente, apresentado de forma conceitual na seção 2.3 e depois analisado por meio de um estudo de caso feito em uma empresa multinacional de grande porte no setor de Bens de Consumo que possui forte presença no mercado nacional (seções 4.1 e 4.2). O produto final dessa análise é uma apresentação sobre os pontos fortes e as oportunidades de melhoria do Funil de Inovação adotado pela empresa, fundamentados a partir de citações de especialistas em Gerenciamento de Projetos, Tecnologia da Informação e Gestão da Inovação (seções 4.3 e 4.4).

Já a seção 3 apresenta os procedimentos metodológicos adotados para o estudo de caso e as seções 2.1 e 2.2, a seguir, apresentam conceitos introdutórios sobre Gestão de Inovação e grupos de processos de Gerenciamento de Projetos.

\section{Fundamentação Teórica}

\subsection{Inovação como ferramenta de geração de valor nas organizações}

O conceito de Inovação refere-se a mudanças, que podem ser relacionadas aos produtos ou serviços que a organização oferece, ou podem estar relacionadas ao modo como a organização cria, produz e entrega seus produtos. Inovação também faz referência à novidade, contexto no qual podem ser diferenciados os conceitos inovação incremental, que trata de melhoramentos sobre o que já foi desenvolvido previamente, ou inovação radical (ou por ruptura), que possui uma base tecnológica e científica, proporcionando desempenhos superiores e transformando a maneira como as soluções atuais são pensadas e utilizadas. Esse último tipo de inovação possui como característica básica um alto grau de novidade [Takahashi 2007].

Estes conceitos sobre inovação se aplicam ao cenário de inovação tecnológica e de processos de TI, sob a óptica da TI como um produto ou serviço que pode ser inovado de maneira incremental ou radical. Contudo, as organizações, incluindo a área de TI, devem buscar inovar de forma sistêmica, ou seja, na busca deliberada e organizada por mudanças, analisando as oportunidades que tais mudanças oferecem para inovação econômica e social.

Segundo Barbieri (2009), um processo de Gestão da Inovação eficaz pode ser definido a partir de três componentes: uma ideia, sua implantação e os resultados 
obtidos a partir de sua implantação. Tais componentes estão representados a seguir na figura 1 .

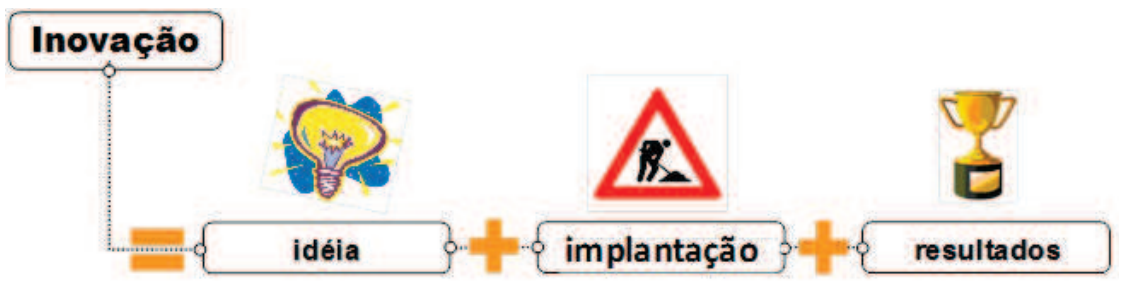

Figura 1. Componentes da Inovação.

Fonte: adaptada de Barbieri (2008).

Conforme representado, a primeira etapa do processo é a ideia de inovação, originada a partir de fatores internos ou externos à organização. Já a implantação é a etapa de desenho e entrega para materializar e trazer para o mundo real os benefícios e oportunidades almejados no momento em que a ideia foi concebida. Ao final do processo, os resultados alcançados são avaliados e comparados às estimativas e expectativas iniciais, a fim de mensurar se a inovação alcançou seus propósitos.

A seguir, serão detalhados os grupos de processos de Gerenciamento de Projetos, sugeridos pelo PMI (2013), a fim de introduzir esse modelo como uma referência formal para viabilizar a gestão do projeto de inovação durante todo o seu ciclo de vida.

\subsection{Grupos de processos em Gerenciamento de Projetos}

Os cinco grupos de processos de Gerenciamento de Projetos sugeridos pelo PMI [PMI 2013], e representados na figura 2, são: Iniciação, Planejamento, Execução, Monitoramento e Controle, e Encerramento. Abaixo segue uma breve descrição sobre cada um deles:

- Iniciação: É onde o projeto é formalmente reconhecido pela organização, que se mobiliza para o início das atividades. É nessa fase que as necessidades e oportunidades são mapeadas em um problema estruturado, que será tratado no decorrer das fases seguintes. Nessa fase ainda é recomendável que o Gerente de Projetos seja alocado e que seus papeis e responsabilidades sejam devidamente formalizados e documentados para toda a organização executora do projeto.

- Planejamento: É onde ocorre o detalhamento de tudo o que será entregue e das atividades e prazos que irão compor o cronograma. Nessa fase, também, os orçamentos de custos do projeto são feitos e submetidos para aprovação. Nesta fase são elaborados os planos de todas as frentes de trabalho do Projeto.

- Execução: Abrange os processos necessários para a coordenação das pessoas e demais recursos no desenvolvimento do trabalho que foi planejado e definido como escopo do Projeto.

- Monitoramento e Controle: Ocorre paralelamente às demais fases e seu propósito é garantir que os objetivos do Projeto sejam atingidos, por meio do acompanhamento contínuo do seu progresso, e também por meio da identificação e endereçamento das mudanças necessárias.

- Encerramento: Consiste na avaliação de todo o trabalho que foi executado, ou seja, na análise final do que foi entregue em relação ao que foi planejado. São feitas 
avaliações de custos finais e de prazo de entrega. É nessa fase também, que ocorre o levantamento das lições aprendidas, onde potencialidades e falhas do projeto são discutidas e documentadas como base de conhecimento que deve compor os ativos organizacionais e ser usada para a execução de novos projetos. A interdependência destas fases está representada na figura 2.

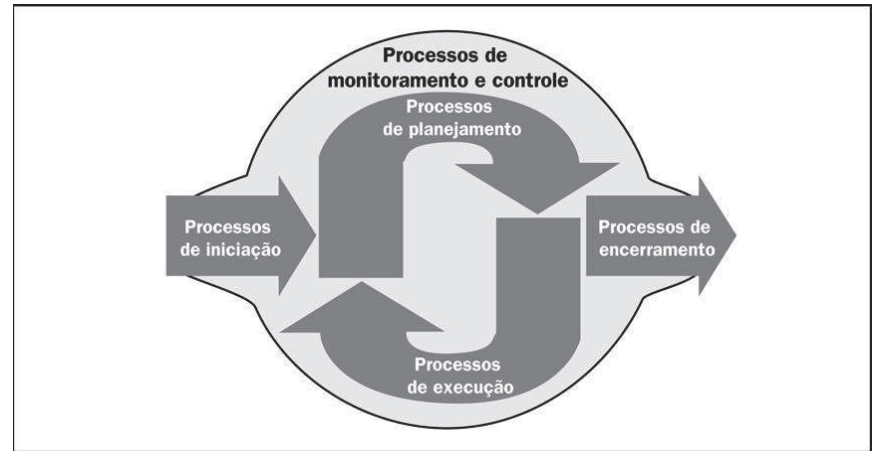

Figura 2. Grupos de processos de Gerenciamento de Projetos. Fonte: PMI (2013).

Em projetos de TI, em especial os de desenvolvimento de software, os grupos de processos costumam receber nomes diferentes, mas os objetivos são os mesmos, como é o caso do modelo de gestão de inovações e projetos de TI que será introduzido a seguir. Essa correlação entre os grupos de processos propostos pelo PMI e os processos do Funil de Inovação é demonstrada em detalhes na seção 4.2 e na figura 5.

\subsection{Conceitos e processos do Funil de Inovação}

Conforme citado, conceitualmente qualquer processo de inovação origina-se de uma ideia inicial que vai agregando uma série de outras ideias no decorrer do tempo, portanto pode-se concluir que a inovação é um processo permeado de ideias em todas as suas etapas. Mesmo depois de finalizado e entregue, o Projeto de Inovação é munido de novas ideias, que o acompanharão no sentido de aperfeiçoar a entrega ao longo de seu ciclo de vida [Barbieri 2009].

Esses conceitos estão previstos no Funil de Inovação, inicialmente adotado pela empresa de Bens de Consumo 3M - mundialmente reconhecida pelo seu potencial em inovação - para a gestão de projetos de novos produtos [Barbieri 2009]. Conforme apresentado na figura 3, o Funil de Inovação [Clark e Wheelwright 1993] possui etapas para gestão do ciclo de vida das inovações, incluindo filtros (marcos) para priorização das mais relevantes. Nessas etapas, as ideias surgem e, caso aprovadas pelo primeiro filtro de priorização, evoluem para um estudo de viabilidade e são submetidas ao segundo filtro de aprovação. Se aprovadas, seguem para as etapas de planejamento, execução e entrega do projeto para que se tornem um novo produto ou serviço. 


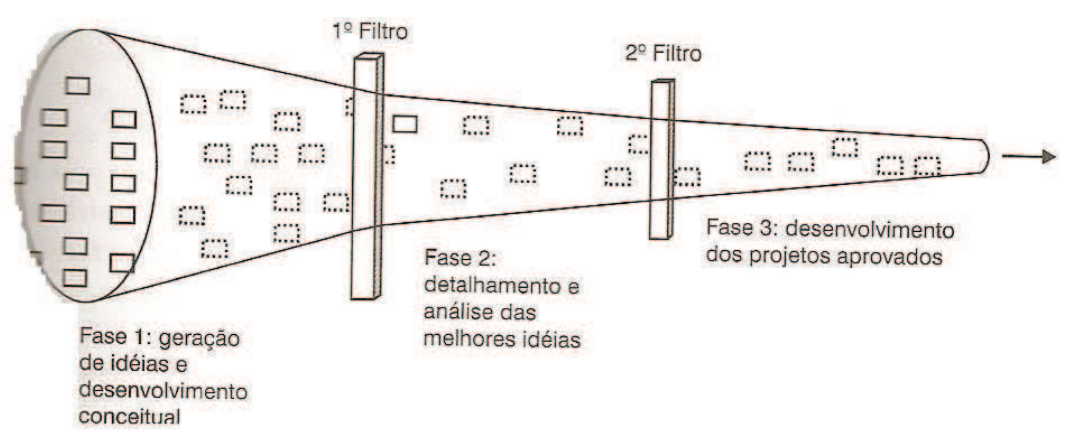

Figura 3. Processos de Gestão da Inovação: modelo do funil. Fonte: Barbieri (2008) apud Clark e Wheelwright (1993).

Outro aspecto importante é que o Funil de Inovação é um interessante modelo para a gestão de inovação em novas tecnologias, de acordo com Barbieri (2009). Considerando as inovações de um modo geral - sejam elas por ruptura ou incrementais - as ideias originais que "entram pela boca do funil" devem surgir em função de duas motivações básicas:

- Problemas, necessidades e oportunidades identificadas pelas áreas de negócio que podem ocorrer internamente e externamente à empresa; e

- Oportunidades vislumbradas a partir da introdução de novos conhecimentos científicos e tecnológicos.

Assim como a 3M, a empresa de Bens de Consumo analisada também usa o Funil de Inovação para gerenciar seus projetos de novos produtos. A justificativa para seu uso se deve ao desafio da empresa ter que priorizar as ideias mais relevantes para entregar produtos inovadores para o exigente e concorrido mercado em que atua. A partir desta premissa básica e a fim de alinhar-se à estratégia do negócio [Laurindo 2008], nada seria mais lógico do que a área de TI da empresa analisada, passar a gerir seus projetos de inovação da mesma forma. E foi exatamente o que a área fez, adaptando o Funil de Inovação como estrutura de processos para o Gerenciamento de Projetos de TI.

Essa visão geral sobre o Funil de Inovação é importante para o estudo de caso apresentado e discutido na seção 4. Antes disso, a seção a seguir apresentará os procedimentos metodológicos utilizados nesse estudo.

\section{Procedimentos metodológicos adotados}

Esse trabalho consiste em uma pesquisa de campo do tipo qualitativa, uma vez que é centrada em classificações e análises dissertativas da unidade incorporada de análise. Além disso, foi escolhida como estratégia de pesquisa a técnica de estudo de caso, devido à peculiaridade de responder, segundo Yin (2010), questões do tipo "como" e "por que". Perguntas do tipo "como" são fundamentais para descrever o caso, de acordo com o contexto do tema proposto. Já as perguntas do tipo "por que" são importantes para a análise da situação ou dos eventos descritos no estudo, com o objetivo de identificar potencialidades e fraquezas nos objetos estudados [Yin 2010]. A partir dessa estrutura, esse estudo visa:

(1) Apresentar a estrutura do Funil de Inovação, de maneira a atender as necessidades em Inovação em TI demandadas pela organização (agentes internos) e pelo mercado que ela atua (agentes externos) e 
(2) explicar porque esse modelo é adotado, analisando suas potencialidades e fraquezas.

O ponto 1 é tratado na seção 4.2 desse artigo, ao passo que o ponto 2 é discutido, com base em fundamentação teórica, nas seções 4.3 e 4.4. A fim de suportar o estudo de caso, foi utilizado um processo em quatro fases, representado na figura 4.

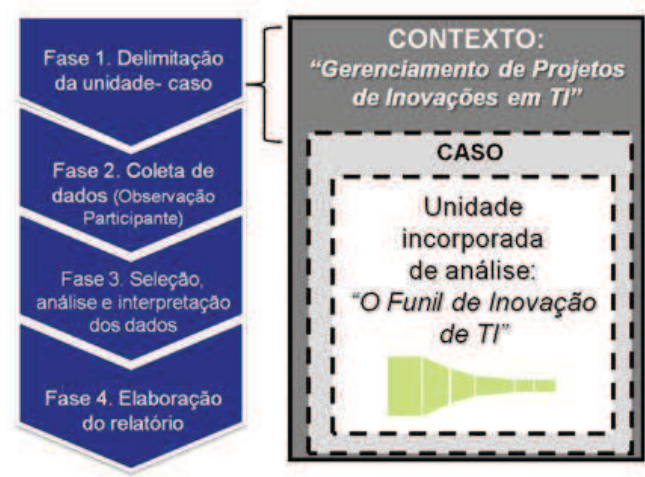

Figura 4. Processo para delineamento de estudo de caso. Fonte: Gil (2010) e Yin (2010).

Na primeira fase da pesquisa, foi delimitada uma única unidade (caso) de estudo, apesar desse modelo de projeto permitir a adição de mais unidades de análise [Yin 2005]. Conforme citado, esse estudo de caso visa descrever e analisar o modelo Funil de Inovação como alternativa de metodologia para execução de projetos de TI.

Durante a fase 2 da pesquisa, onde ocorreu a coleta de dados do estudo, foi usada a técnica observação participante que, segundo Yin (2010), possui vantagens por se tratar de uma análise em tempo real e contextual dos fatos e por apresentar uma percepção dos comportamentos e razões interpessoais do cenário analisado. Sendo assim, é válido ressaltar que um dos autores deste estudo levantou as informações para o estudo de caso durante sua atuação como desenhista de processos e suporte a treinamentos e comunicações do projeto de implantação do modelo em 2008. Posteriormente, utilizou o Funil de Inovação de TI durante os quatro anos seguintes em que trabalhou como membro de equipe e Gerente de Projetos na organização analisada, usando essas experiências também como fonte de informações para sua observação participante. Nesse período, a organização executora utilizou a metodologia para gerir mais de quinhentos projetos de TI na região Américas e o observador participante trabalhou em cerca de vinte deles.

As fases 3 e 4 foram paralelas. Na fase 3, foram selecionados dados com base em documentação sobre o modelo Funil de Inovação de TI da empresa analisada, além das informações coletadas na observação participante, a fim de propiciar a apresentação e a análise crítica do modelo. Essa etapa foi fundamentada a partir de referências bibliográficas produzidas por especialistas em Gerenciamento de Projetos, Gestão da Inovação e Tecnologia da Informação, selecionadas devido ao alinhamento com o contexto, caso e unidade incorporada de análise. Com relação à elaboração do relatório (Fase 4), foi definida uma estrutura para o artigo que oferecesse, primeiramente, uma fundamentação teórica sobre o contexto, seguida pela descrição e análise do estudo de caso. A seguir será apresentada brevemente a empresa analisada e seu cenário interno, com destaque para a estrutura da sua área de TI. 


\section{Estudo de caso: o Funil de Inovação como modelo formal para priorizar e executar projetos de TI}

\subsection{A empresa analisada e sua área de TI}

A empresa analisada iniciou suas atividades no Brasil no final da década de 1920. No início, eram comercializados apenas produtos importados da Inglaterra, seu país sede, especialmente sabão em pó e sabonetes. A empresa apresentou dificuldades para entrar no mercado nacional pelo fato do Brasil ser um país preponderantemente agrícola na época. Contudo, se consolidou ao longo das décadas como uma das principais empresas com atividade no país, agregando ao seu portfólio de produtos marcas nacionais por meio de aquisições. Atualmente é considerada líder do mercado de Bens de Consumo no país, nos ramos de alimentos, cuidados pessoais e higiene e limpeza.

Apesar de a área de TI da empresa possuir a característica de suportar o negócio ela configurou-se globalmente, no decorrer dos últimos dez anos, como uma grande parceira para a ativação das estratégias e para melhoria da eficiência operacional. Na última década, por exemplo, foram executados projetos para implantação de softwares ERP (Sistema Integrado de Gestão Empresarial) em várias unidades de negócio ao redor do mundo, com destaque para a iniciativa na América Latina, cujo projeto ocorreu entre os anos de 2001 e 2006.

A área de TI é gerida sob uma perspectiva de unidade de negócio independente, com núcleo administrativo, áreas de Recursos Humanos e Financeiro próprias. Em algumas localidades possui até um escritório separado dos demais processos de negócio da empresa, como é o caso do escritório localizado na cidade de São Paulo, que abriga os profissionais que oferecem serviços de TI para a unidade de negócio do Brasil e para toda a América Latina. Toda essa estrutura é organizada sobre as perspectivas de relacionamento com os demais processos de negócio e empresas terceiras provedoras de tecnologias e aplicações, além da gestão dos serviços e planejamento e execução de projetos de TI. Essa última perspectiva da estrutura de TI da empresa é a patrocinadora do modelo comentado a seguir.

\subsection{A empresa analisada e sua área de TI}

Essa adaptação do modelo de Funil de Inovação para a área de TI deu-se a partir de sua combinação com os processos de gestão de ciclo de vida de Projetos apresentado pelo PMI, definidos na Seção 3 deste artigo. Essa comparação entre o Funil de Inovação e os processos para gestão do ciclo de vida de Projetos proposto pelo PMI está representada na figura 5 . 


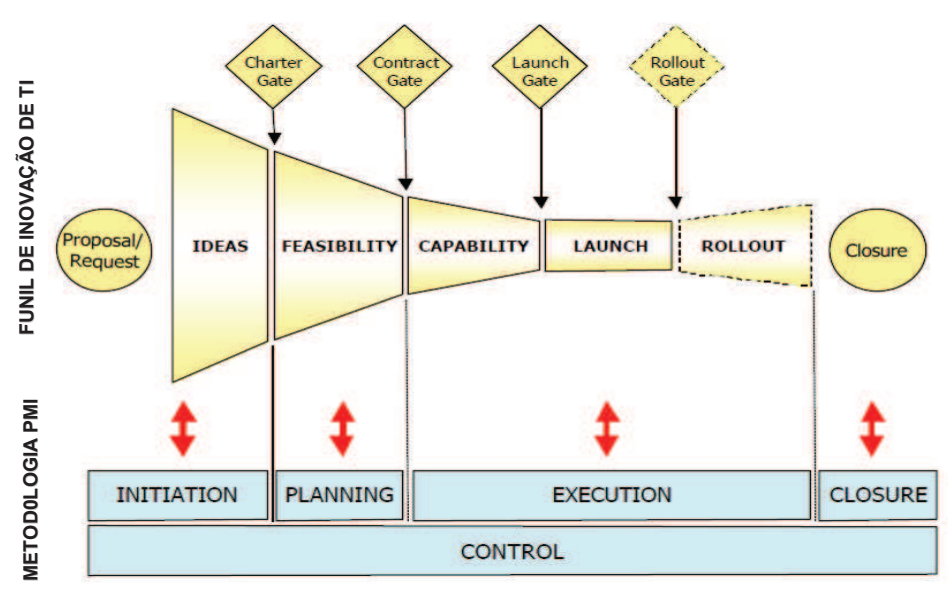

Figura 5. Funil de Inovação de $\mathrm{Tl}$ e os processos de gerenciamento de projetos.

Fonte: Documentação da empresa analisada (2012).

- Fase de Proposal/Request: essa é a etapa onde a ideia surge e ganha o mínimo de formalismo para que inicie como uma nova entrada do Funil de Inovação;

- Fase de Ideas: nessa etapa é onde o documento Project Charter - ou "termo de abertura do projeto" [PMI 2013] - é desenvolvido e a ideia ganha um esboço mais detalhado sobre como será executada incluindo os custos em alto nível, principais riscos, premissas, restrições, partes interessadas e quem será o responsável por conduzir o Projeto. Conforme demonstrado na Figura 5, essa fase é equivalente à de Iniciação proposta pelo PMI;

- Fase de Feasibility: nessa etapa é feito o planejamento mais robusto e detalhado do projeto, para garantir um maior nível de detalhe e assertividade sobre os pontos definidos na fase de Ideas. O fim de Feasibility é marcado pela elaboração do Contract, documento muito semelhante ao plano de gerenciamento do projeto proposto pelo PMI (2013), o que justifica ser esta fase equivalente ao grupo de processos de Planejamento;

- Fase de Capability: essa é a etapa onde o trabalho para criação do produto ou serviço a ser entregue pelo projeto é executado;

- Fase de Launch: nessa etapa todas as atividades de Go-Live, ou lançamento, do Projeto são executadas para que o produto ou serviço seja entregue;

- Fase de Rollout: essa é uma etapa opcional, executada especialmente em projetos onde há, primeiramente, um produto ou serviço piloto lançado que, posteriormente, será entregue também para outras localidades ou unidades de negócio. A partir dessa premissa, cada Rollout pode incorporar apenas algumas ou todas as etapas do Funil de Inovação;

- Fase de Closure: nessa etapa o projeto é formalmente encerrado e atividades importantes como fechamento financeiro, coleta de lições aprendidas e liberação da equipe são executadas, sendo comparável ao grupo de processos de Encerramento proposto pelo PMI (2013).

Ainda sobre a comparação entre os modelos Funil de Inovação e o proposto pelo PMI (2013), pode-se notar que o Funil de Inovação diferencia-se por possuir marcos 
que são eventos que dão visibilidade para a conclusão de uma determinada atividade importante ou fase do Projeto. São esses marcos:

- Charter Gate: É o marco que representa a submissão do Project Charter para aprovação. Se o Project Charter é aprovado, o projeto segue para a fase de Feasibility. É importante mencionar que dificilmente um projeto é reprovado nesse primeiro marco;

- Contract Gate: Esse marco representa a submissão do Contract para aprovação. Caso seja reprovado, o projeto é postergado para outro período ou encerrado, seguindo algumas das etapas propostas pela fase de Closure como, por exemplo, liberação da equipe que já estava alocada nele. Em caso de aprovação, o projeto adquire os recursos financeiros estimados para que seja executado;

- Launch Gate: Nesse marco todos os critérios para lançamento das entregas do projeto são verificados, a fim de validar se realmente o lançamento pode ser feito. Um exemplo de critério, específico em projetos onde há configuração ou desenvolvimento de sistemas, são os testes de liberação que fazem uma última verificação da qualidade do sistema em ambiente produtivo;

- Rollout Gate: Esse marco determina o início de um novo Rollout.

É pertinente mencionar que, na empresa analisada, os projetos são avaliados e priorizados por fóruns e comitês formados por executivos de TI e outros grupos formados por executivos de processos e unidades de negócio. De acordo com Weill \& Ross (2006), esse arquétipo de Governança de TI chama-se Duopólio de TI e possui a característica de equilibrar as decisões e disputas de poder entre todas as unidades de negócio, colocando os executivos de TI como agentes centrais, que intermediam a priorização conforme a estratégia e necessidades de toda a empresa e não só de grupos isolados. Contextualizando, os comitês possuem caráter local e regional, conforme abaixo:

- Comitês locais: na unidade de negócios brasileira, por exemplo, o comitê é composto pelo presidente da empresa no país e os vice-presidentes dos processos de negócio de Finanças, Vendas, Marketing, Cadeia de Suprimentos, entre outros, além do Diretor de TI para Brasil. Esse modelo é o mesmo para o México e para as sub-regiões de Cone Sul (Argentina, Chile, Paraguai, Uruguai e Bolívia) e AnCam (países Andinos e América Central), totalizando, portanto, quatro comitês locais.

- Comitê regional: um comitê composto pelos executivos de TI e dos processos de negócio com autoridade regional conduz o fórum de priorização dos projetos que impactam grupos de países ou todo o continente.

A seguir serão abordados aspectos positivos e oportunidades de melhoria para os processos do Funil de Inovação de TI.

\subsection{Aspectos positivos do Funil de Inovação de TI}

Para o caso prático de uso do Funil de Inovação estudado, a quantidade de ideias de projetos de TI submetidos ao Funil de Inovação em determinado período é maior do que a quantidade de recursos disponíveis para execução, o que torna necessária a priorização e escolha dos projetos mais necessários e estratégicos. Mesmo aumentando a taxa de sucesso dos projetos e a eficácia do gerenciamento (Souza et al, 2012) Essa priorização traz o risco das demandas mais necessárias à organização não serem 
escolhidas. Com o objetivo de diminuir essas falhas, o Funil de Inovação de TI traz consigo inúmeros marcos (gates) de aprovação (já detalhados na seção anterior deste artigo) para que os benefícios que o projeto propõe para a empresa sejam avaliados, geralmente, em duas oportunidades.

A figura abaixo representa a comparação entre o sistema de Gestão de Inovação proposto por Barbieri (2009) e o Funil de Inovação [Clark e Wheelwright 1993]. Nesta comparação, pode ser destacada outra potencialidade oferecida pelo Funil de Inovação relacionada à venda, ou entrega, das soluções que a área de TI desenvolve para os demais processos de Negócio. Esses esforços de venda compreendem a modelagem conjunta do escopo, a fim de evitar desalinhamento entre o demandante e o executor do Projeto, e esforços de adoção das soluções como treinamentos e preparação para lançamento. Esse fluxo compreende os esforços necessários para que a ideia seja gerida e viabilizada como uma inovação até que esteja apta a gerar receitas para a organização executora [Barbieri 2009].

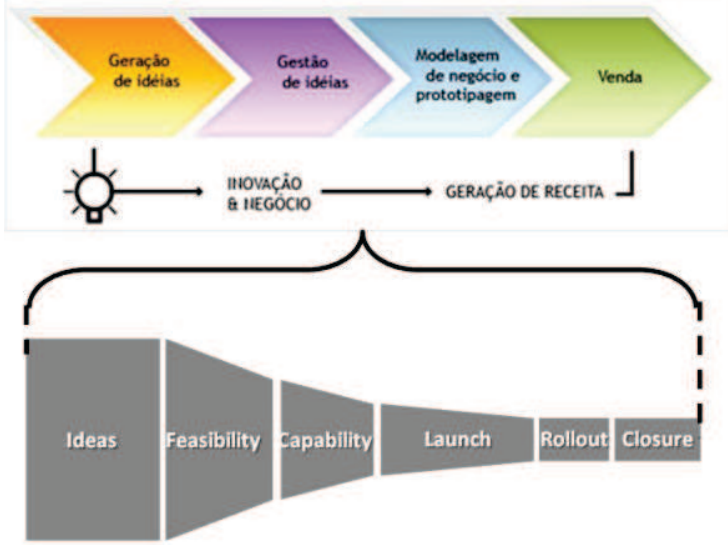

Figura 6. Analogia entre a Gestão de Inovação e o Funil de Inovação de TI. Fonte: adaptado de Barbieri (2009) apud Clark e Wheelwright (1993).

Esses aspectos positivos e todos os processos do Funil de Inovação de TI demandam esforços de melhoria contínua para continuarem aderentes às necessidades do negócio e da área de TI. As principais fraquezas do modelo, que poderiam fazer parte desse pacote de melhorias, foram destacadas a seguir.

\subsection{Oportunidades de melhoria para o Funil de Inovação de TI}

Segundo o PMI (2013), a maioria dos problemas identificados durante a execução de um Projeto é decorrente de uma iniciação inadequada. Por isso, os processos do funil de Inovação exigem muito rigor para sua execução, principalmente os processos de Iniciação (Ideas) e Planejamento (Feasibility). Este atributo, apesar de trazer o benefício de melhoria da qualidade e diminuição de riscos, torna muito rigorosa e onerosa a execução de projetos do Portfólio considerados menores ou menos complexos, causando consideráveis impactos no grupo de processos de gerenciamento do tempo do projeto [PMI 2013]. Essa falta de flexibilidade do Funil de Inovação de TI para o gerenciamento dos diferentes tipos e tamanhos de projetos é apontada pelos membros da organização estudada como o grande ponto de fraqueza do modelo.

Além disso, por ser composto por uma grande quantidade de processos e controles, o Funil de Inovação é difícil de ser assimilado por novos funcionários da empresa ou por iniciantes das atividades de Gerenciamento de Projetos na área de TI, 
incluindo usuários-chave ou outras partes interessadas que precisam conhecer o modelo. Cardoso (2013) apud Bititci (1995) defende a importância do processo e seu sistema de controle ser "facilmente inteligível para os funcionários".

Outra dificuldade apresentada pelo modelo é ocasionada pela grande quantidade de pessoas responsáveis - no caso da organização estudada mais de duzentas pessoas de quinze diferentes países na América Latina - que devem suportar, serem responsáveis, serem informadas ou que devem ser consultadas durante a execução dos projetos. Isso provoca um considerável impacto nos processos de gerenciamento de comunicações e, consequentemente, de tempo dentro dos projetos.

Além dos inúmeros esforços de treinamento e reciclagem que a organização executa periodicamente para garantir o uso mais adequado possível do Funil de Inovação de TI, esforços de criação de versões mais enxutas e ágeis do modelo para uso em projetos mais simples ou com requisitos em aberto vêm sendo conduzidos pela organização. Essa flexibilidade tão desejada tem sido discutida exatamente no âmbito de enxugar os processos de Iniciação (Proposal/Request e Ideas) e Planejamento (Feasibility) para os projetos menores, sob a premissa básica de que o planejamento não deve ser tão rigoroso devido aos baixos riscos, impactos e custos que costumam gerar para a empresa. Segundo Marçal et al. (2013), o uso de metodologias ágeis trazem à organização maior flexibilidade, agilidade e simplicidade e exigem uma mudança de cultura para serem amplamente adotadas.

\section{Conclusão}

Este artigo apresentou o Funil de Inovação como uma proposta de modelo formal para o Gerenciamento de Projetos de TI. Tal modelo é capaz de oferecer à área de TI os marcos necessários para priorização dos projetos mais relevantes, além de propiciar um processo comum para a gestão do ciclo de vida dos projetos de TI da empresa analisada. Ambos aspectos são os principais pontos fortes do modelo.

Além de expor esse caso prático de uso do Funil de Inovação de TI, este artigo apresentou uma breve análise sobre as oportunidades de melhoria que ele apresenta. Um deles é que o modelo demanda alta necessidade de integração e comunicação entre as diferentes áreas executoras de projetos, o que torna complexo o Gerenciamento das Comunicações [PMI 2013]. Uma forma de minimizar esse impacto seria delegar maior autoridade aos gerentes de projeto, que são os principais agentes para tomada de decisão. Essa ação, conforme Dessein (2002), contribui para acelerar o fluxo das comunicações em situações onde há baixo nível de conflito.

Outro ponto de melhoria já citado é que o modelo exige uma intensa e contínua difusão do conhecimento sobre os processos e acerca da distribuição de papéis e responsabilidades definidos, a fim de garantir que novos membros de equipe, gerentes de projeto e partes interessadas estejam sempre alinhados sobre essas formas de trabalho. Esses treinamentos poderiam ser planejados para ocorrer periodicamente e não de maneira ad hoc, como ocorre atualmente. Laudon e Laudon (2013) classificam como significativos os esforços contínuos de treinamento para promover a adoção e coletar de forma recorrente os benefícios da adoção de um processo.

Além disso, mais um ponto de melhoria importante, é a necessidade de enxugar os processos do Funil de Inovação para a execução de projetos menores, a fim de reduzir o tempo para entrega dessas iniciativas mais simples e de baixo impacto e risco 
para o negócio. Conforme exposto, tais esforços já estão em curso na organização estudada.

Apesar dos resultados obtidos com a análise do modelo, um fator foi limitante para uma maior amplitude desse estudo: não houve comparação do cenário atual com o cenário prévio à adoção do Funil de Inovação de TI, o que forneceria uma análise mais profunda sobre os benefícios alcançados a partir da sua adoção.

Por fim, e com base na limitação do estudo citada, observa-se como oportunidade futura de estudo comparar esse caso prático de uso do Funil de Inovação de TI com outro modelo de Gerenciamento de Projetos de TI adotado por empresa com perfil semelhante à que foi alvo desse estudo, estabelecendo métricas para avaliar e comparar a efetividade de ambos os modelos para a gestão do ciclo de vida dos projetos de inovações em TI.

\section{Referências bibliográficas}

Barbieri, J. C. e Alvares, A. C. T. (2009) Gestão de ideias para inovação continua. Bookman, $1^{\text {a }}$ edição.

Berre, A. J. et al. (2013) Open Business Model, Process and Service Innovation with VDML and ServiceML. In IWEI Workshop proceedings. Volume X - No. X/2013, pages 1-14.

Cardoso, P. A. (2013) "Identificação de um Sistema de Medição de Desempenho para Gestão de Projetos em Redes de Colaboração." Revista Mundo Project Management, p. 45.

Clark, K. B. Wheelwright, S. C. (1993) Managing new product and process development. Free Press, $1^{\text {st }}$ edition.

Dessein, W. (2002) "Authority and Communication in Organizations." In Review of Economic Studies. Volume 69, pages 811 to 838.

Gil, A.C. (2010) Como elaborar projetos e pesquisa. Atlas, $5^{a}$ edição.

Helena, A. e Medeiros, F. (2009) "Diferenciando os Alinhamentos Estratégicos de Projetos." Revista Mundo Project Management, p. 15.

Laudon, K. C. and Laudon, J. P. (2013) Management Information Systems. Pearson Prentice Hall, $13^{\text {th }}$ edition.

Marçal, M. (2013) "Como o PMO pode utilizar metodologias ágeis com sucesso." Revista Mundo Project Management, p. 40.

Project Management Institute. (2013) A Guide to the Project Management body of knowledge: PMBok.Guide. Project Management Institute, Inc, $5^{\text {th }}$ edition.

Souza, A. D. (2012) "Uma Abordagem para Gerência Estratégica de Portfólio com Foco na Seleção de Projetos" In Simpósio Brasileiro de Sistemas de Informação. Volume VIII, 2009.

Takahashi, S. (2007) Gestão de Inovação de Produtos: Estratégia, processo, organização e conhecimento. Elsevier, $1^{a}$ edição.

Vanhaverbeke, W. (2013) "Rethinking Open Innovation Beyond the Innovation Funnel." http://timreview.ca/article/673, January.

Weill, P. and Ross, J. W. (2006) IT Governance: How Top Performers Manage IT Decision Rights for Superior Results. Harvard Business Review Press, $2^{\text {nd }}$ edition.

Yin, R. K. (2010) Estudo de Caso: planejamento e métodos. Bookman, $4^{\mathrm{a}}$ edição. 